\title{
Mulemba
}

Revista Angolana de Ciências Sociais

5 (10) | 2015

Angola 40 anos de independência: memória, identidades, cidadania e desenvolvimento

\section{Para um melhor entendimento da obra Manual prático de Demografia, de Manuel Félix}

Mingiedi Zinga

\section{(2) OpenEdition \\ Journals}

Edição electrónica

URL: http://journals.openedition.org/mulemba/2154

DOI: 10.4000/mulemba.2154

ISSN: 2520-0305

Editora

Edições Pedago

\section{Edição impressa}

Data de publição: 1 novembro 2015

Paginação: 809-815

ISSN: 2182-6471

Refêrencia eletrónica

Mingiedi Zinga, «Para um melhor entendimento da obra Manual prático de Demografia, de Manuel Félix», Mulemba [Online], 5 (10) | 2015, posto online no dia 13 outubro 2018, consultado o 26 janeiro 2021. URL: http://journals.openedition.org/mulemba/2154 ; DOI: https://doi.org/10.4000/mulemba. 2154 


\section{Para um melhor entendimento da obra Manual prático de Demografia, de Manuel Félix ${ }^{*}$}

\section{Mingiedi Zinga ${ }^{* *}$}

É com muita satisfação que aceitei o convite para fazer a apresentação do livro do Mestre Manuel Félix, cujo título é Manual prático de Demografia.

Quando vi a obra pensei desde logo que ela fosse o resultado de um trabalho de tese, mas depois lhe dar uma pausada vista de olhos, sobretudo na biografia do seu autor, compreendi que estava longe de ser o resultado da tese para um grau académico, não obstante o seu autor, para além de ser engenheiro de minas, ser também gestor.

A escrita deste ensaio foi provocada em primeiro lugar por docentes que administraram matérias ligadas à população ao longo de vários seminários em que o autor terá participado. Estes, deixaramlhe com toda a certeza uma referência incontornável que o conduziu para essa direcção. O contacto com vários autores clássicos no

* Texto da apresentação pública da obra Manual prático de Demografia, de Manuel Félix (Luanda, Mayamba Editora, 2015, 284p. [«Kunyonga»]), efectuada no dia 30 de Outubro de 2015 (Sexta-feira), no Anfiteatro principal da Faculdade de Ciências Sociais (FCS) da Universidade Agostinho Neto (UAN), por ocasião do $v$ Colóquio de Ciências Sociais: Angola 40 Anos de Independência: Memória, Identidades, Cidadania e Desenvolvimento, realizado em Luanda na FCS nos dias 29 e 30 de Outubro de 2015.

** Demógrafo, é Professor Associado e Chefe do Departamento de Ciências Auxiliares e Práticas Profissionais (DCAPP) da Faculdade de Ciências Sociais (FCS) da Universidade Agostinho Neto (UAN). 
campo da demografia não deram a Manuel Félix outra opção senão a de envolver-se em corpo e alma na busca de mais e mais conhecimentos sobre a matéria referente a população. $O$ crescente interesse pelo conhecimento das leis do desenvolvimento da população, conduziu à produção deste manual prático.

Ao longo da leitura deste manual, constatei que ele é composto por treze capítulos, contendo 39 tabelas, 15 gráficos e um total de 282 páginas. Nesses capítulos estão versadas matérias variadas de interesse demográfico, que vão ajudar o leitor - sobretudo estudante, mas também e porque não, professor -, a consolidar os seus conhecimentos sobre a disciplina da demografia.

Este manual assenta sobretudo na compilação de conhecimentos sobre a população, conhecimentos esses que terão sido produzidos por distintos autores ao longo do desenvolvimento da disciplina da Demografia enquanto ciência. Nele encontramos múltiplas contribuições, desde mercantilistas populacionistas tais como Achilli Guillard (1799-1876), John Grauent (1620-1674), Jakob Bernoulli (1654-1705), Galileo Galilei (1564-1642), Alfred Robert Wallace (1823-1913), Adam Smith (1723-1790), David Ricardo (1772-1823), Thomas Robert Malthus (1766-1834) e anti-malthusianos, etc., até autores contemporâneos como Jean-Bourgeois Pichat (1912-1990), Adolphe Landry (1934-), Roland Pressat (1923-), Serge Bourgeat e tantos outros.

É óbvio que não é possivel apresentar todos capítulos aqui, mas os interessados no estudo da população terão essa oportunidade de conhecer as matérias versadas em todos os capítulos, bastando para tal que comprem o livro e se entreguem à sua leitura. Por isso, aqui vamos escolher apenas alguns capítulos para serem divulgados.

Começando pelo capítulo três, aqui o autor desenvolve questões relacionadas com fontes de dados como, por exemplo, o censo populacional, contagem permanente dos registos da população, in810 quéritos por amostragem, etc. $\mathrm{O}$ quinto capítulo trata da matéria ligada a coeficientes demográficos. Segundo o autor, o coeficiente demográfico é uma unidade genérica que expressa a relação entre características opostas, a sua estrutura, os processos demográficos, ou seja, factos que estão relacionados com particularidades das pessoas. Por isso, é claro que o número de eventos observados depende do número da população total.

Os indicadores numéricos da população são normalmente fornecidos num determinado momento, por exemplo, no início, meio, 
fim do ano, etc. No capítulo vi, o autor apresenta-nos os indicadores de crescimento e sobrecrescimento numérico populacional. Os indicadores do crescimento da população estão claramente relacionados com a mudança numérica da população ao longo do tempo. Diferencia-se entre os indicadores de crescimento da população e sobrecrescimento da população.

O indicador de sobrecrescimento da população pode ser apresentado em unidades absolutas e relativas. Entre as absolutas encontram-se os indicadores do crescimento total absoluto, aumento natural e crescimento migratório.

As taxas relativas de sobrecrescimento podem ser expressas em indicadores do tempo de sobrecrescimento e em coeficientes. Apresenta em tabelas a evolução da população mundial desde 1900 a 1999. Apresenta também uma tabela que reflecte os paísess mais populosos do mundo até 2001.

No capítulo vII, o autor desenvolve estudos sobre a natalidade. Presta especial atenção aos conceitos de natalidade, ao seu papel na reprodução da população, taxas de fecundidade, taxas de reprodução como medidas elementares no estudo da intensidade de nascimentos dentro de uma dada população. Não esqueceu de fazer referência ao grau de fecundidade da mulher angolana dizendo o seguinte: "Angola é um país com grande dinâmica das taxas de crescimento demográfico. As médias e as anuais são relativamente altas, indiciando que a população angolana ainda se encontra numa fase ascendente de transição demográfica. Este elevado ritmo de crescimento da população pode resultar da conjugação das elevadas taxas de fertilidade com a relativa regressão nas taxas gerais de mortalidade» (FÉLIX 2015: 128).

Para ilustar melhor os níveis de natalidade, o autor apresentanos uma tabela que reflecte as taxas brutas de natalidade de alguns países tanto africanos como asiáticos. Nessa tabela demostra que a taxa bruta de natalidade das populações angolanas é de 43,69 por cada 1000 cidadãos. Em outra tabela, o autor apresenta-nos os níveis de fecundidade dos países estudados na tabela anterior. Segundo os dados da tabela, a fecundidade da mulher angolana é de 6,12 filhos (por cada mulher).

No capítulo viII, como é óbvio, Manuel Félix incluiu os factores de mortalidade e motivos das mortes, taxas brutas de mortalidade, diagrama de lexis, mortalidade tipo, tábuas de mortalidade, etc. Apresenta algumas fórmulas, realiza alguns exercícios elementares 
relativos a mortalidade para orientar o leitor; apresenta também várias tabelas que reflectem os níveis de mortalidade.

No capítulo referente a nupcialidade, o autor procura dar a definição daquilo que é hoje considerado casamento moderno, definindo-o do modo seguinte: «casamento moderno é uma união livre e voluntária, com direitos iguais entre homens e mulheres, tudo na base do amor e do respeito mútuo, para a criação de uma família e gerando direitos e obrigações mútuos dos cônjuges, projectada para o nascimento e educação dos filhos» (FÉLIX 2015: 178).

Procurou estudar também a idade mínima fixada para o casamento, apontando exemplos extraídos de diferentes países. Um facto que chama a nossa atenção é o autor escrever na sua obra que a idade mínima para as mulheres vai de 9 aos 20 anos e, para os homens, de 14 a 22 anos. De acordo com a lei, parece certo que a idade varia de um país para outro. Por exemplo, na Hungria e Polónia, a idade mínima para o casamento está circunscrita aos 18 anos para homens e 16 anos para as mulheres; na Inglaterra, ninguém se pode casar com uma pessoa com menos de 16 anos de idade; em França, os mínimos são de 15 anos para as mulheres e 18 anos para os homens; na China, eles só podem casar aos 22 anos (maioridade para o casamento) e elas aos 20 anos; na Índia, os mínimos exigidos são os 21 anos para os homens e 18 anos para as mulheres; nos Estados Unidos da América, a idade mínima varia de um Estado para outro. Para os homens 14-18 anos e para as mulheres, 13-17 anos; no Quebec, Canadá, o limite mínimo de idade para o casamento situa-se, para as raparigas, entre 12-16 anos, e nos rapazes, entre 14-16 anos; na Argentina, Colômbia e Peru, a idade mínima para o casamento para homens está fixada nos 16 anos de idade e para as mulheres nos 14 anos; já na Venezuela, Paraguai, Chile e Equador, os homens podem casar-se a partir dos 14 anos e as mulheres a partir dos 12 anos; na Nigéria e Kenya, as raparigas podem casar-se aos 9 anos 812 e os rapazes aos 16-18 anos; em Angola, a idade mínima são os 18 anos par ambos os sexos; no que toca ao casamento tradicional, a idade não assume carácter importante, sendo necessário, no entanto, o consentimento dos pais.

A idade de casamento tem interessse principalmente em termos de reprodução da população porque constitui um dos factores associados a natalidade. Neste capítulo, o autor calcula também as taxas elementares de nupcialidade, apresentando algumas tabelas e uma tábua de nupcialidade. 
Falando da nupcialidade, não podia deixar de se prestar uma especial atenção ao divórcio, e isso porque casamento e divórcio são dois fenómenos opostos na vida da população. Lá onde se efectivam uniões, são certamente esperadas separações por vários motivos. O casamento pode ser dissolvido por motivo de divórcio ou morte de um dos cônjuges. A demografia considera o término do casamento como uma relação entre dois processos: o divórcio e a viuvez. Os divórcios estão intimamente ligados ao casamento e têm métodos de registos semelhantes no que respeita a sua descrição. Os principais parâmetros de descrição são:

- Número absoluto de divorciados: divorciados por duração, tempo de duração do casamento antes do divórcio, nacionalidade, local de residência, etc. (FÉLIX 2015: 193).

- Duração média do casamento antes do divórcio;

- Intensidade do divórcio.

São apresentadas algumas tabelas que ilustram a natureza dos divórcios numa determinada cidade.

O autor aponta também os motivos do divórcios. Vejamos alguns deles:

- Corrupção moral;

- Grosseria, negligência dos deveres;

- Carácter deformado de um dos cônjuges;

- Estabelecimento ou presença de uma outra familia;

- Alcoolismo;

- Adultério;

- Infertilidade de um dos cônjuges, etc.

No entanto, a demografia interessa-se sobretudo por analisar os elementos objectivos dos factores de divórcios, tais como:

- Anos de casamento;

- Relação entre a idade dos cônjuges;

- Frequência relativa de divórcios no primeiro casamento, leva a segundas ou mais núpcias, que podem também elas dissolver-se.

No capítulo xI, o autor estuda a estrutura etária da população. Presta especial atenção a estrutura da população por sexo. Segundo o 
autor, o estudo da estrutura da população por idade e sexo permite--nos analisar o processo de mudança de gerações, o que, por sua vez, possibilita que sejam efectuadas previsões sobre o total da população.

Assim, devem ser consideradas as seguintes características básicas da estrutura etária:

- A proporção numérica de homens e mulheres por grupos etários;

- A proporção de mulheres em idade fértil (15-49 anos);

- A proporção de crianças e adolescentes (o-19 anos);

- O peso específico do contigente em idade activa (25-59 anos);

- O peso específico de idosos (mais de 60 anos) da população total.

Angola é um país em que o número das mulheres supera o dos homens. $\mathrm{O}$ índice de masculinidade (racio homens/mulheres é de 94). Isto significa que existem 94 homens por cada 100 mulheres. Esta tendência é comum em todas as províncias, com excepção para a Província da Lunda-Norte.

O autor apresenta também várias pirâmides e entre elas uma que reflecte a estrutura da população angolana. Dá também uma especial atenção ao envelhecimento da população. Acerca disso escreve o seguinte: «o envelhecimento da população é constituido pelos seguintes factores:

- Redução da natalidade;

- Crescimento da mortalidade infantil;

- Redução da mortalidade dos idosos;

- Saída dos jovens no processo de migração;

- Perda irrecuperável de população em idade activa nas guerras» (FÉLIX 2015: 213).

No capítulo XII, o autor estuda a migração. Dentre a matéria estudada neste capítulo uma delas é a migração internacional.

A migração internacional da população é vista como um movimento territorial da população através das fronteiras governamentais. Os objectivos destes movimentos são muito diferentes:

- Encontrar um novo lugar de residência, de trabalho ou de estudo;

- Treino, repouso ou tratamento médico; 
- Fugir de um conflito político, étnico, racial;

- Perseguições ou desastres económicos ou climáticos.

Eis aqui, em resumo, tudo quanto pude entender da leitura da obra do Mestre Manuel Félix, e que explanei aqui para vosso entendimento. Espero, por isso, que esta obra tenha muitos leitores e que os estudantes interessados encontrem o que procuram neste seu manual.

\section{Mingiedi Zinga}

Demógrafo, é Professor Associado e Chefe do Departamento de Ciências Auxiliares e Práticas Profissionais (DCAPP) da Faculdade de Ciências Sociais (FCS) da Universidade Agostinho (UAN), onde ensina as cadeiras de Demografia e Filosofia, no âmbito da graduação. Doutor em Demografia (1997) pelo Instituto de Demografia da Academia das Ciências da Bulgária, Mestre em Filosofia (1989) e Licenciado em Filosofia (1989), ambos os graus pelo Instituto Superior de Ciências Sociais da Bulgária. As suas áreas de interesse são: Estudos da população (Explosão demográfica; As políticas demográficas aplicadas à realidade angolana); Questões de Filosofia (A imortalidade da alma; As contradições filosóficas marxistas; O papel do Tocoísmo no despertar da mente do africano na conquista da liberdade e dignidade) e Análises no âmbito das Ciências Sociais (Angola e o pacto social; As Ciências Auxiliares ao serviço da Faculdade de Ciências Sociais).

[e-mail: mingiediphd-2014@outlook] 